Note. This article will be published in a forthcoming issue of the International Journal of Sports Physiology and Performance. The article appears here in its accepted, peer-reviewed form, as it was provided by the submitting author. It has not been copyedited, proofread, or formatted by the publisher.

Section: Original Investigation

Article Title: Influence of Isoinertial-Pneumatic Mixed Resistances on Force-Velocity Relationship

Authors: Simon Avrillon ${ }^{1}$, Boris Jidovtseff ${ }^{2}$, François $\mathrm{Hug}^{3}$, and Gaël Guilhem ${ }^{1}$

Affiliations: ${ }^{1}$ French Institute of Sport (INSEP), Research Department, Laboratory Sport, Expertise and Performance (EA 7370) Paris, France. ${ }^{2}$ University of Liège, Department of Sport and Rehabilitation Sciences, Liège, Belgium. ${ }^{3}$ University of Nantes, Faculty of Sport Sciences, Laboratory Movement, Interactions, Performance (EA 4334), Nantes, France.

Journal: International Journal of Sports Physiology and Performance

Acceptance Date: June 14, 2016

(C)2016 Human Kinetics, Inc.

DOI: $\underline{\text { http://dx.doi.org/10.1123/ijspp.2016-0226 }}$ 


\title{
Influence of isoinertial-pneumatic mixed resistances on force-velocity relationship
}

Type of Article: ORIGINAL INVESTIGATION

\author{
Simon AVRILLON ${ }^{1}$, Boris JIDOVTSEFF ${ }^{2}$, François HUG $^{3}$, Gaël GUILHEM ${ }^{1 *}$ \\ ${ }^{1}$ French Institute of Sport (INSEP), Research Department, Laboratory Sport, Expertise and \\ Performance (EA 7370) Paris, France \\ ${ }^{2}$ University of Liège, Department of Sport and Rehabilitation Sciences, Liège, Belgium \\ ${ }^{3}$ University of Nantes, Faculty of Sport Sciences, Laboratory Movement, Interactions, \\ Performance (EA 4334), Nantes, France
}

\section{*Correspondence and reprints:}

Gaël Guilhem, PhD

Institut National du Sport, de l'Expertise et de la Performance

Département de la Recherche

Laboratoire Sport, Expertise et Performance (EA 7370)

11, avenue du Tremblay

75012 Paris

France

Tel: +33(0)1 41744336

Fax: +33 (0)1 41754535

e-mail: gael.guilhem@insep.fr

Preferred running-head: MIXED RESISTANCES TO MODULATE POWER OUTPUT

Word count for abstract: 250

Word count for main text: $\mathbf{3 5 0 0}$

Figures: 4 
"Influence of Isoinertial-Pneumatic Mixed Resistances on Force-Velocity Relationship"

by Avrillon S, Jidovtseff B, Hug F, Guilhem G]

International Journal of Sports Physiology and Performance

(C) 2016 Human Kinetics, Inc.

\section{Abstract}

Purpose: Muscle strengthening is commonly based on the use of isoinertial loading, whereas variable resistances such as pneumatic loading may be implemented to optimize training stimulus. The purpose of the present study was to determine the effect of the ratio between pneumatic and isoinertial resistance on the force-velocity relationship during ballistic movements. Methods: A total of 15 participants performed two concentric repetitions of ballistic bench press movements with intention to throw the bar at 30\%, 45\%, 60\%, 75\%, and $90 \%$ of the maximal concentric repetition, with five resistance ratios including $100 \%, 75 \%$, $50 \%, 25 \%$ or $0 \%$ of pneumatic resistance, the additional load being isoinertial. Force-, velocity- and power-time patterns were assessed and averaged over the concentric phase to determine the force-velocity and power-velocity relationships for each resistance ratio. Results: Each 25\% increase in pneumatic part in resistance ratio elicited higher movement velocity $\left(+0.11 \pm 0.03 \mathrm{~m} . \mathrm{s}^{-1}\right.$ from $0 \%$ to $80 \%$ of the concentric phase) associated with lower force levels $(-43.6 \pm 15.2 \mathrm{~N})$. Increased isoinertial part in resistance ratio resulted in higher velocity towards the end of the movement $\left(+0.23 \pm 0.01 \cdot \mathrm{m} \cdot \mathrm{s}^{-1}\right.$ from $90 \%$ to $\left.100 \%\right)$. Conclusion: Our findings show that resistance ratio could be modulated to develop the acceleration phase and force towards the end of the concentric phase (pneumatic-oriented resistance). Inversely, isoinertial-oriented resistance should be used to develop maximal force and maximal power. Resistance modality could therefore be considered as an innovative variable to modulate the training stimulus according to athletic purposes.

Key words: variable resistance, constant load, exercise modality, force-velocity relationship, maximal power 
"Influence of Isoinertial-Pneumatic Mixed Resistances on Force-Velocity Relationship"

by Avrillon S, Jidovtseff B, Hug F, Guilhem G]

International Journal of Sports Physiology and Performance

(C) 2016 Human Kinetics, Inc.

\section{INTRODUCTION}

Resistance training has long been performed through the application of an external load on targeted muscle groups ${ }^{1}$. The determination of the optimal load for enhancing muscle capacity requires a knowledge of the fundamental force-velocity relationship that determines power-generating capacity of the muscle and the force-velocity levels involved during specific sport tasks ${ }^{2-4}$. This relationship is classically established by measuring force and associated movement velocity under various constant isoinertial loads ${ }^{5}$. The slope of this relationship permits to give valuable information about the individual balance between force and velocity capabilities ${ }^{6}$.

Isoinertial loading elicits muscle contractions similar to those observed during dailylife tasks in which the muscle exerts a force to accelerate a mass. As such, the magnitude of the force required to generate movement depends on inertia. Light loads are thus used to generate similar movement velocities than those observed during explosive performance. In the absence of load projection, an extended deceleration phase is needed, which ultimately leads to a decreased velocity towards the end of the movement ${ }^{7-9}$. Overall, contractions under isoinertial load are effective for generating maximal force during the initiation of the movement ${ }^{10,11}$. However, the ability to generate force decreases with the increase in velocity of the displaced load. Therefore, constant loading does not provide an appropriate training stimulus to generate force at high velocity ${ }^{8,10}$.

Pneumatic resistance is one alternative that has been developed to overcome the aforementioned limitations associated with the use of isoinertial load. Pneumatic loading consists of generating variable resistance resulting from air compressed in a cylinder ${ }^{12}$. Using this technique (pneumatic resistance), the only inertia that needs to be overcome is related to the mass of the mobilized body segments, limiting the amount of force required to initiate the movement ${ }^{13,14}$. As a consequence, higher velocities can be reached as the decrease in force is 
"Influence of Isoinertial-Pneumatic Mixed Resistances on Force-Velocity Relationship"

by Avrillon S, Jidovtseff B, Hug F, Guilhem G]

International Journal of Sports Physiology and Performance

(C) 2016 Human Kinetics, Inc.

limited towards the end of the concentric phase ${ }^{13}$, therefore allowing maximization of the velocity component of the F-V relationship. Inversely isoinertial exercise (being ballistic or not) results in higher force levels towards the initial phase of the movement. It is therefore likely that the optimal trade-off between isoinertial and pneumatic loading (i.e., in $\%$ of the total resistance) should change as a function of the required neuromuscular adaptations ${ }^{15}$. Although recent studies investigated the force and velocity patterns elicited by pneumatic and isoinertial loading during the concentric displacement ${ }^{13,14}$, the effect of the ratio between both resistances on force- and power-velocity relationship is still unknown.

The purpose of the present study was to determine the effect of the ratio between pneumatic and isoinertial resistance on movement patterns and force-velocity-power relationships during bench-press. We hypothesized that isoinertial resistance would affect the force-velocity relationship towards a force component while pneumatic resistance would affect the slope of the relation towards a velocity-oriented profile. The knowledge gained by this study will provide crucial information for coaches to adapt a ratio for specific athletic purposes.

\section{METHODS}

Subjects

A total of 15 healthy males $(25 \pm 1 \mathrm{yr}, 179 \pm 5 \mathrm{~cm}, 74 \pm 10 \mathrm{~kg})$ with no previous history of upper limb injury volunteered to participate in this study. Each participant was engaged in physical activity and has previous resistance training experience $(3.9 \pm 4.3 \mathrm{yr}$, 1RM: $77.2 \pm 17.6 \mathrm{~kg}$ ). They were informed regarding the nature, aims, and risks associated with the experimental procedure before they gave their written consent to participate. The study was approved by the local ethical committee and conducted in accordance with the Declaration of Helsinki. 
"Influence of Isoinertial-Pneumatic Mixed Resistances on Force-Velocity Relationship"

by Avrillon S, Jidovtseff B, Hug F, Guilhem G]

International Journal of Sports Physiology and Performance

(C) 2016 Human Kinetics, Inc.

\section{Experimental design}

Participants attended two familiarization sessions to accustomize to the testing procedures and one test session. Bench-press movements were performed on a bench positioned in the center of a rack (Rack 3111, Keiser, Fresno, CA, USA). Isoinertial resistance was calculated by adding the mass of the barbell and the bumper plates that were weighted before the experiment. Pneumatic resistance was produced by a compressor (1022, Keiser, Fresno, CA, USA) regulating the pressure of compressed air into pneumatic cylinders. This load was applied to the barbell by cables and pulleys provided by the manufacturer (Fig. 1A).

\section{Procedures}

Quantification of pneumatic load. The relationship between pneumatic and isoinertial load was determined during a pilot session. Using a strain gauge (Enertec Schlumberger, Montrouge, France), the amount of pneumatic force applied to the barbell was measured at eight different levels of pneumatic resistance as provided by the device $(4.9,10$, $20,30,40,60,80,92.8 \mathrm{~kg}$ ). For each measure, we divided the measured force value by the gravitational component $\left(9.81 \mathrm{~N} \cdot \mathrm{kg}^{-1}\right)$ to obtain a theoretical mass $\left(\mathrm{m}_{i}\right.$, in $\left.\mathrm{kg}\right)$. A linear regression (Equation $\left.1, \mathrm{R}^{2}=0.99\right)$ between the theoretical mass $\left(\mathrm{m}_{i}\right)$ and the pneumatic mass $\left(\mathrm{m}_{p}\right)$ provided by the device was used to determine the amount of displayed pneumatic resistance required to impose a targeted resistive force:

$$
m_{p}=0.9184 \times m_{i}+0.8057
$$

Bench press movement. The bench press movement was standardized to ensure the reproducibility of our measurements during each session. Participants feet were consistently in contact with the floor and hands were placed on the barbell while the elbow angle at $90^{\circ}$ $\left(0^{\circ}=\right.$ full elbow extension $)$. For each attempt, the participants lowered the barbell until a 
"Influence of Isoinertial-Pneumatic Mixed Resistances on Force-Velocity Relationship"

by Avrillon S, Jidovtseff B, Hug F, Guilhem G]

International Journal of Sports Physiology and Performance

(C) 2016 Human Kinetics, Inc.

minimal distance of $1 \mathrm{~cm}$ over the chest, immobilized the barbell for $1 \mathrm{~s}$ then pushed the barbell. The position of hands, shoulders, back and feet were marked with tape, and the distance between the barbell and the chest was controlled by a piece of plastic foam attached to the bar.

The assessment of the force-velocity relationship requires that maximal ballistic contractions are performed. In addition, ballistic actions maximize power output during concentric-only contractions. Therefore, participants pushed the bar maximally throughout the range of motion with the intention to throw the bar when possible.

Familiarization. During the familiarization session, participants were accustomed to the resistance modalities and experimental procedures. The maximal load that participants were able to lift once during a concentric bench-press (1RM) was also determined. After a standardized warm-up, they were instructed to complete 3 repetitions at 15, 30, 45 and 60\% of their estimated 1RM in the considered modality, and 2 repetitions at $75 \%$ and $90 \% 1 \mathrm{RM}$ with $3 \mathrm{~min}$ of rest between each set. Then, they performed one attempt with $2.5 \mathrm{~kg}$ increments, until they reached their $1 \mathrm{RM}$. The $1 \mathrm{RM}$ was defined as the last load lifted by the participants over the entire range of motion.

Test Session. The test session aimed to assess the force-velocity relationship during five conditions that differed in their ratio between pneumatic and isoinertial resistance: $100 \%$ pneumatic-0\% isoinertial (100P), 0\%-100\% (100I), 25\%-75\% (25P75I), 50\%-50\% (50P50I) and $75 \%-25 \%$ (75P25I). Standardized warm-up included 5 minutes of rowing at $100 \mathrm{~W}, 2$ sets of 10 repetitions at 30\% 1RM and 1 set of 6 repetitions at $60 \% 1 \mathrm{RM}$. Then, for each condition, participants had to perform two repetitions at 30,45, 60, 75 and $90 \% 1 \mathrm{RM}$ in a randomized order to limit the effect of fatigue. The duration of the rest period was adapted to the amount of external load displaced (i.e., $1 \mathrm{~min}$ at $30 \% 1 \mathrm{RM}, 1 \mathrm{~min} 30 \mathrm{~s}$ at $45 \%$ 1RM, 2 $\min$ at $60 \% 1 \mathrm{RM}, 2 \mathrm{~min} 30 \mathrm{~s}$ at $75 \% 1 \mathrm{RM}$ and $3 \mathrm{~min}$ at $90 \% 1 \mathrm{RM})$. 
"Influence of Isoinertial-Pneumatic Mixed Resistances on Force-Velocity Relationship"

by Avrillon S, Jidovtseff B, Hug F, Guilhem G]

International Journal of Sports Physiology and Performance

(C) 2016 Human Kinetics, Inc.

\section{Data collection and processing}

Barbell displacement was measured with a linear transducer (PT5A-150, Celesco, Chatsworth, CA) that was vertically positioned over the barbell. The signal was digitized at $1000 \mathrm{~Hz}$ using a 12-bit analog to digital converter (DT 9804, Data Translation, Marlboro, MA). All analyses were performed using a custom written script (Origin 2015, OriginLab Corporation, Northampton, MA). Position was low-pass filtered $\left(10 \mathrm{~Hz}, 3^{\text {rd }}\right.$ order Butterworth). The vertical displacement $\left(\mathrm{d}_{\mathrm{z}}\right)$ of the barbell was differentiated to calculate instantaneous velocity (vz). Velocity was then differentiated to calculate instantaneous acceleration (az). Force was calculated using the following equation (2):

$$
F=m \times\left(a_{z}+g\right)+F_{P N E}
$$

Where $\mathrm{m}$ is the external mass (barbell + plates in $\mathrm{kg}$ ), $\mathrm{g}$ is the gravitational acceleration (in $\left.\mathrm{m} \cdot \mathrm{s}^{-2}\right)$. Pneumatic force $\left(\mathrm{F}_{\mathrm{PNE}}\right.$, in $\left.\mathrm{N}\right)$ was measured during the concentric phase using proprietary software (A420 Keiser, Keiser, Fresno, CA) as follows:

$$
F=P \times A
$$

where $\mathrm{P}$ is the air pressure (in $\mathrm{Pa}$ ) and $\mathrm{A}$ is the area through which the air is compressed (in $\mathrm{m}^{2}$ ). The excellent reproducibility of the measurements was previously demonstrated by Frost et al. ${ }^{13}$.

Power output $\left(\mathrm{P}_{0}\right.$ in $\left.\mathrm{W}\right)$ was then calculated as the product between force and velocity.

This experimental design was previously tested during free-weight exercises and the validity of force, velocity and power measurements obtained with a linear transducer was verified by our group and others ${ }^{16,17}$.

Mechanical signals were time-reversed to determine the onset of the concentric phase, as the first time point corresponding to a zero velocity, starting from the time point 
"Influence of Isoinertial-Pneumatic Mixed Resistances on Force-Velocity Relationship"

by Avrillon S, Jidovtseff B, Hug F, Guilhem G]

International Journal of Sports Physiology and Performance

(C) 2016 Human Kinetics, Inc.

corresponding to the peak force value (Figure 1B). Then, mechanical signals were timereversed a second time to determine the offset of the concentric phase as the minimal force produced by the subject, starting from the onset of the concentric phase (Figure 1B). A linear interpolation technique was used to normalize the mechanical data (force, velocity, power) as a percentage of the same concentric distance (the maximal range of motion completed in all conditions). Mean mechanical parameters were calculated over this range of motion to determine the relation between force, velocity and power for all conditions (Figure 1C). A linear regression was applied to the relation between force and velocity to determine the yand $\mathrm{x}$-intercept that corresponded to maximal theoretical force $\left(\mathrm{F}_{0}\right.$ in $\left.\mathrm{N}\right)$ and maximal theoretical velocity $\left(\mathrm{v}_{0}\right.$ in $\left.\mathrm{m} \cdot \mathrm{s}^{-1}\right)$, respectively (Figure $\left.1 \mathrm{C}\right)$. The slope of the measured profile $\left(\mathrm{S}_{\mathrm{FV}}\right)$ was calculated as follows:

$$
S_{F V}=-\frac{F_{0}}{V_{0}}
$$

A second-degree polynomial regression was applied to determine the relation between power and velocity (Figure $1 \mathrm{C})$. Maximal theoretical power $\left(\mathrm{P}_{\max }\right.$ in $\left.\mathrm{W}\right)$ was determined as the peak value of the regression.

\section{Statistical analyses}

All statistical analyses were conducted using Statistica version 7.1 (StatSoft, Tulsa, OK) and Matlab (version R2015a, The Mathworks, Natick, MA). Data distributions were first checked by the Shapiro-Wilk normality test. All data being normally distributed, differences in force and velocity patterns were tested using a wavelet-based functional ANOVA ${ }^{18}$. The advantage of this method is to reduce the number of statistical tests required without affecting statistical power. The procedure was applied using specific Matlab codes (Matlab, The Mathworks, Natick, MA, USA). Briefly, force and velocity patterns were transformed to the wavelet domain ( $3^{\text {rd }}$ order Coiflet wavelet, with periodic extension), and ANOVAs were 
"Influence of Isoinertial-Pneumatic Mixed Resistances on Force-Velocity Relationship"

by Avrillon S, Jidovtseff B, Hug F, Guilhem G]

International Journal of Sports Physiology and Performance

(C) 2016 Human Kinetics, Inc.

performed on the individual wavelet coefficients. To evaluate significant differences across ratios (i.e., wavelet coefficient corresponding to the initial $\mathrm{F}$ tests at significant level $\propto=$ 0.05), we used a Scheffe post-hoc test. Wavelet coefficients that were significantly different between conditions were back transformed to obtain significant difference curves (Fig. 2-3, dashed traces). Inspection of the force-velocity and power-velocity relationships revealed that a load of $30 \% 1 \mathrm{RM}$ elicited mean power values that were the closest to $\mathrm{P}_{\max }$ for all the ratio conditions. For the sake of clarity, the impact of resistance ratio on velocity and force patterns were therefore tested for 30\% 1RM. Separate one-way ANOVAs for repeated measures were used to test the potential effect of resistance ratio on $F_{0}, V_{0}, S_{F v}$ and $P_{\text {max }}$. When the sphericity assumption was violated (Mauchly test), a Geisser-Greenhouse correction was used. When a main effect or interaction was found, Bonferroni post hoc tests were performed. For all tests, the significance level was set at $P<0.05$.

\section{RESULTS}

Contrasts in the temporal domain identified across resistance ratios

Velocity. Visual inspection of velocity traces suggested that velocity in the middle phase of the concentric phase increased with increases in pneumatic resistance, whereas the gradual increase in isoinertial resistance elicited higher movement velocity toward the end of the movement (e.g., Fig. 2 D-H, dashed trace). When considering the middle of the concentric phase, a significant lower velocity was found at 100I compared to $100 \mathrm{P}(-0.52 \pm$ $0.28 \mathrm{~m} . \mathrm{s}^{-1}$ from $20 \%$ to $79 \%$ of the concentric phase $)$ and $75 \mathrm{P} 25 \mathrm{I}\left(-0.35 \pm 0.13 \mathrm{~m} . \mathrm{s}^{-1}\right.$ from $43 \%$ to $83 \%$ of the concentric phase). During the same portion of the movement, a significant higher velocity was found for 100P than 75P25I (+0.26 $\pm 0.28 \mathrm{~m}^{-1} 1$ from 35 to $\left.63 \%\right)$, 50P50I $\left(+0.33 \pm 0.35 \mathrm{~m} . \mathrm{s}^{-1}\right.$ from 27 to $\left.75 \%\right)$ and 25P75I $\left(+0.51 \pm 0.29 \mathrm{~m} . \mathrm{s}^{-1}\right.$ from 19 to $80 \%$ ). During the end of the concentric phase, a higher velocity was found at 100I in 
"Influence of Isoinertial-Pneumatic Mixed Resistances on Force-Velocity Relationship"

by Avrillon S, Jidovtseff B, Hug F, Guilhem G]

International Journal of Sports Physiology and Performance

(C) 2016 Human Kinetics, Inc.

comparison with $100 \mathrm{P}\left(+0.39 \pm 0.35 \mathrm{~m} . \mathrm{s}^{-1}\right.$ from $83 \%$ to $\left.100 \%\right)$. Pure pneumatic loading (100P) elicited slower movement velocity than 75P25I $\left(-0.48 \pm 0.44 \mathrm{~m} \cdot \mathrm{s}^{-1}\right.$ from $83 \%$ to $100 \%), 50 \mathrm{P} 50 \mathrm{I}\left(-0.54 \pm 0.41 \mathrm{~m} \cdot \mathrm{s}^{-1}\right.$ from $87 \%$ to $\left.100 \%\right)$ and $25 \mathrm{P} 75 \mathrm{I}\left(-0.51 \pm 0.36 \mathrm{~m} \cdot \mathrm{s}^{-1}\right.$ from $87 \%$ to $100 \%)$.

Force. Mean differences in force patterns are depicted in Figure 3. Pure isoinertial loading (100I) generated higher force output than 100P $(+179.9 \pm 60.6 \mathrm{~N}$ from $0 \%$ to $90 \%$ of the concentric phase), $75 \mathrm{P} 25 \mathrm{I}(+146.5 \pm 49.3 \mathrm{~N}$ from $0 \%$ to $94 \%), 50 \mathrm{P}-50 \mathrm{I}(+113.3 \pm 47.7 \mathrm{~N}$ from $0 \%$ to $94 \%)$ and $25 \mathrm{P} 75 \mathrm{I}(+65.6 \pm 42.4 \mathrm{~N}$ from $0 \%$ to $86 \%)$. During the same portion of the movement, a significant higher force output was found for 50P50I $(+86.8 \pm 45.6 \mathrm{~N}$ from $8 \%$ to $75 \%)$ and $25 \mathrm{P} 75 \mathrm{I}(+124.3 \pm 55 \mathrm{~N}$ from $0 \%$ to $82 \%)$ compared to $100 \mathrm{P}$. In contrast, during the end of the concentric phase, 100P elicited higher force values than 100I $(+78.5 \pm$ $99.2 \mathrm{~N}$ from $97 \%$ to $100 \%), 25 \mathrm{P} 75 \mathrm{I}(+109.7 \pm 99.6 \mathrm{~N}$ from $95 \%$ to $100 \%)$ and $50 \mathrm{P} 50 \mathrm{I}$ $(+130.8 \pm 91.6 \mathrm{~N}$ from $92 \%$ to $100 \%)$. No other significant differences were found between the tested conditions.

\section{Force-velocity and power-velocity relationships}

We observed a main effect of resistance ratio on the slope of the force-velocity relationship $(P=0.006)$. This slope was significantly lower at 100P than 50P50I $-326.5 \pm$ $136 ; P=0.005), 25 \mathrm{P} 75 \mathrm{I}(-280.1 \pm 87.2$ vs. $-363.9 \pm 128.7 ; P<0.001)$, and $100 \mathrm{I}(-280.1 \pm$ 87.2 vs. $340.3 \pm 112.2 ; P=0.007)$. No significant differences in slope were found between the other conditions. There was a main effect of ratio on $\mathrm{F}_{0}, \mathrm{~V}_{0}$ and $\mathrm{P}_{\max }(P<0.003) . \mathrm{F}_{0}$ was significantly higher with $100 \mathrm{I}(788 \pm 250 \mathrm{~N})$ compared to 50P50I $(+11 \pm 10 \%), 75 \mathrm{P} 25 \mathrm{I}(+12$ $\pm 8)$, and 100P $(+20 \pm 23 \% ; P<0.01)$. Moreover, $\mathrm{F}_{0}$ obtained at $100 \mathrm{P}(651 \pm 202 \mathrm{~N})$ was significantly lower than that obtained at 50P50I $(+8 \pm 18 \%)$, and 25P75I $(+12 \pm 28 \%$; $P<$ 0.008). Compared to 25P75I, a significant higher $\mathrm{V}_{0}$ was found with $100 \mathrm{P}(+14 \pm 11 \%, P=$ 
"Influence of Isoinertial-Pneumatic Mixed Resistances on Force-Velocity Relationship"

by Avrillon S, Jidovtseff B, Hug F, Guilhem G]

International Journal of Sports Physiology and Performance

(C) 2016 Human Kinetics, Inc.

0.007). $\mathrm{P}_{\max }$ obtained with the 100I condition $(472.2 \pm 101.3 \mathrm{~W})$ was significantly higher than the values produced under modalities that included pneumatic resistance $(+18 \pm 4 \%,+16 \pm$ $8 \%,+17 \pm 5 \%$, and $+18 \pm 8 \%$, compared to $25 \mathrm{P} 75 \mathrm{I}, 50 \mathrm{P} 50 \mathrm{I}, 75 \mathrm{P} 25 \mathrm{I}$ and $100 \mathrm{P}$, respectively; $P<0.001)$. No other significant differences were obtained between the tested conditions.

\section{DISCUSSION}

The aim of the present study was to investigate the effect of a resistance ratio between pneumatic and isoinertial resistance on movement kinetics and kinematics during benchpress. On the basis of an original statistical analysis, the major finding of the study is that gradual modulation of resistance ratio influenced the amount of force and velocity generated throughout the concentric phase of a ballistic movement. The increase in pneumatic resistance resulted in higher velocity associated with lower force levels in the middle of the concentric phase. Inversely, the increase in isoinertial loading elicited higher velocity towards the end of the movement. As a consequence, the force-velocity relationship was oriented towards force (with isoinertial resistance) or velocity (with pneumatic resistance) capacity. These results are useful for determining the optimal resistance modality according to an individual profile and for training purposes.

Some methodological considerations should be kept in mind when interpreting the data. First, due to the type of the resistance and the characteristics of the movement (ballistic action), slight variations in range of motion were observed between conditions when the shoulders failed to remain in contact with the bench. In this context, the data processing employed in the present study considered the range of motion that was completed in all tested conditions. On the basis of results from a pilot experiment, we applied the same amount of total external force in each condition, regardless of the resistance ratio. This procedure was chosen to consider the effect of resistance ratio on movement mechanics in standardized 
"Influence of Isoinertial-Pneumatic Mixed Resistances on Force-Velocity Relationship"

by Avrillon S, Jidovtseff B, Hug F, Guilhem G]

International Journal of Sports Physiology and Performance

(C) 2016 Human Kinetics, Inc.

conditions (i.e., with the same movement amplitude and total resistive force). In a view to overcome the well-known limitations of classical statistical methods regarding the comparison of signal patterns, we used original statistical analysis ${ }^{18}$ to consistently compare the entire force-time and velocity-time curves between loading conditions. This procedure showed differences in the shape and magnitude of force and velocity signals throughout the concentric phase without loss of temporal resolution.

Our results showed that the effect of resistance ratio on velocity and force patterns was not homogeneous throughout the movement. The amount of pneumatic resistance increased movement velocity from the beginning to the middle of the concentric phase while the level of force was higher over the same phase as part of the isoinertial load increased (Fig. 2A and 3A). Of note, the present force values were smaller, but consistent with the results of Frost et al. ${ }^{13}$ showing that pneumatic resistance permitted one to reach higher peak acceleration (mean difference of 177\%) and mean velocity (mean difference of $23 \%$ ) than ballistic isoinertial resistance. These differences among resistance ratios could be mainly related to the significant influence of inertia on movement kinetics ${ }^{19}$. Using isoinertial resistance, the amount of force the individual has to produce to initiate the movement must exceed the weight of the load. With pneumatic resistance, this level of force solely depends on the mass of the barbell and body segments involved during the concentric phase. The progressive inclusion of pneumatic loading in the present study gradually reduced the influence of inertia and limited the magnitude of initial force required to displace the barbell $^{11,12,14}$. As a consequence, in the initial part of the movement, pneumatic resistance favored accelerative high-velocity movements, whereas an isoinertial load elicits a higher amount of force.

In contrast, when considering the end of the concentric phase, pure isoinertial and pure pneumatic modalities were the most effective means to induce high level of force, with 
"Influence of Isoinertial-Pneumatic Mixed Resistances on Force-Velocity Relationship"

by Avrillon S, Jidovtseff B, Hug F, Guilhem G]

International Journal of Sports Physiology and Performance

(c) 2016 Human Kinetics, Inc.

slight higher values with pneumatic resistance (Fig. 3 F-H). This outcome resulted from two different mechanical schemes. In line with the literature, isoinertial resistance permitted one to reduce the deceleration phase by throwing the barbell into free space ${ }^{7,9,20}$. This extension of the acceleration phase limited the effect of momentum over the end of the movement compared to non-ballistic actions ${ }^{21,22}$. Inversely, pneumatic resistance is not related to the inertia and momentum of the load, theoretically limiting the effect of velocity variations ${ }^{12}$. Resistive force resulting from the application of pneumatic resistance is thus relatively constant throughout the movement, as reflected by the highest amount of force in the last moments of the concentric phase obtained in the present study.

These differences in velocity-time and force-time curves subsequently affect the shape of the force-velocity relationship. Our findings showed that force and power output were systematically higher under only-isoinertial ratio. Constant external loading seems to therefore remain the more appropriate mechanical stimulus to maximize muscle power when movement is performed as a ballistic action (Fig. 4A). Moreover, the slope of the forcevelocity relationship measured in pure pneumatic conditions exhibits a profile oriented towards velocity capabilities when compared to resistance modalities that include isoinertial resistance. For the same amount of external resistance, movement velocity was consistently higher as the amount of pneumatic part in total resistance increased. This is corroborated by the fact that the velocity measured under pure pneumatic loading at $30 \% 1 \mathrm{RM}\left(1.54 \mathrm{~m} . \mathrm{s}^{-1}\right.$ on average) was remarkably superior to that produced with a larger part consisting of isoinertial loading (1.30 m.s $\mathrm{s}^{-1}$ with a pure constant load). Thus, the inclusion of pneumatic resistance appears to be the most conducive means to allow the production of force at high movement velocities. 
"Influence of Isoinertial-Pneumatic Mixed Resistances on Force-Velocity Relationship"

by Avrillon S, Jidovtseff B, Hug F, Guilhem G]

International Journal of Sports Physiology and Performance

(c) 2016 Human Kinetics, Inc.

\section{CONCLUSIONS \& PRACTICAL APPLICATIONS}

Numerous studies have investigated the power-load spectrum to determine an optimal load to maximize mean power output ${ }^{7,23-26}$. According to the specificity of resistance training, muscular adaptations may be maximized at the movement velocity involved during the exercise $^{27}$. On the basis of our results, exercises including pneumatic resistance could contribute to training velocity-generating capacity, especially in the initial part of the movement. This resistance modality seems appropriate to stimulate the velocity component of the force-velocity relationship and potentially changes the orientation of the slope towards velocity capabilities. Conversely, the use of isoinertial resistance in ballistic actions could allow for development of velocity capacity toward the end of the movement. Regarding the force component of the relation, our findings confirm that the greater the isoinertial load in total resistance, the higher the amount of produced force. Constant external loading will therefore be more prone to modify the slope of the force-velocity relationship towards the force-generating capacity.

A recent approach suggests that an optimal ratio exists between force and velocity, which can contribute to maximizing ballistic performance ${ }^{28,29}$. On the one hand, given that our findings demonstrate the significant impact of resistance ratio on force and movement velocity, the type of resistance modality can be considered as an interesting exercise variable that can be adjusted to induce the targeted gains in force or velocity. On the other hand, for athletes with similar maximal power capability, a significant imbalance between force and velocity capacities can negatively impact their respective ballistic performance ${ }^{30}$. Consequently, practitioners may adapt mechanical stimulus (i.e., resistance modality) based on an athlete's athletic capacities and on-field requirements. 
"Influence of Isoinertial-Pneumatic Mixed Resistances on Force-Velocity Relationship"

by Avrillon S, Jidovtseff B, Hug F, Guilhem G]

International Journal of Sports Physiology and Performance

(C) 2016 Human Kinetics, Inc.

\section{ACKNOWLEDGMENTS}

The authors are grateful to Dr. Antoine Couturier for his valuable input on data processing. S.

Avrillon was supported by a scholarship funded by the French Ministry of Research. 
"Influence of Isoinertial-Pneumatic Mixed Resistances on Force-Velocity Relationship"

by Avrillon S, Jidovtseff B, Hug F, Guilhem G]

International Journal of Sports Physiology and Performance

(C) 2016 Human Kinetics, Inc.

\section{References}

1. American College of Sports Medicine position stand. Progression models in resistance training for healthy adults. Med Sci Sports Exerc. 2009;41(3):687-708.

2. Jaric S. Force-velocity Relationship of Muscles Performing Multi-joint Maximum Performance Tasks. Int J Sports Med. 2015;36:699-704.

3. Giroux C, Rabita G, Chollet D, Guilhem G. Optimal Balance Between Force and Velocity Differs Among World-Class Athletes. J Appl Biomech. 2016;32:59-68.

4. Rabita G, Dorel S, Slawinski J, et al. Sprint mechanics in world-class athletes: a new insight into the limits of human locomotion. Scand J Med Sci Sports. 2015;25:583594.

5. Hill AV. The Heat of Shortening and the Dynamic Constants of Muscle. Proc Biol Sci. 1938;126:136-195.

6. Morin JB, Samozino P. Interpreting Power-Force-Velocity Profiles for Individualized and Specific Training. International journal of sports physiology and performance. 2016;11(2):267-272.

7. Cronin JB, McNair PJ, Marshall RN. Force-velocity analysis of strength-training techniques and load: implications for training strategy and research. $J$ Strength Cond Res. 2003;17:148-155.

8. Cormie P, McCaulley GO, McBride JM. Power versus strength-power jump squat training: influence on the load-power relationship. Med Sci Sports Exerc. 2007;39:996-1003.

9. Newton RU, Kraemer WJ, Häkkinen K, Humphries BJ, Murphy AJ. Kinematics, kinetics, and muscle activation during explosive upper body movements. J Appl Biomech. 1996;12:31-43.

10. Wilson GJ, Newton RU, Murphy AJ, Humphries BJ. The optimal training load for the development of dynamic athletic performance. Med Sci Sports Exerc. 1993;25:12791286.

11. Frost DM, Cronin J, Newton RU. A biomechanical evaluation of resistance: fundamental concepts for training and sports performance. Sports Med. 2010;40:303326.

12. Keiser DL, Inventor; US Patents, assignee. Pneumatic exercising device. 1981, 1981.

13. Frost DM, Cronin JB, Newton RU. A comparison of the kinematics, kinetics and muscle activity between pneumatic and free weight resistance. Eur J Appl Physiol. 2008;104:937-956.

14. Peltonen H, Häkkinen K, Avela J. Neuromuscular responses to different resistance loading protocols using pneumatic and weight stack devices. J Electromyogr Kinesiol. 2013;23:118-124.

15. Baker DG, Newton RU. Effect of kinetically altering a repetition via the use of chain resistance on velocity during the bench press. J Strength Cond Res. 2009;23:19411946. 
"Influence of Isoinertial-Pneumatic Mixed Resistances on Force-Velocity Relationship"

by Avrillon S, Jidovtseff B, Hug F, Guilhem G]

International Journal of Sports Physiology and Performance

(C) 2016 Human Kinetics, Inc.

16. Crewther BT, Kilduff LP, Cunningham DJ, Cook C, Owen N, Yang GZ. Validating two systems for estimating force and power. Int J Sports Med. 2011;32(4):254-258.

17. Giroux C, Rabita G, Chollet D, Guilhem G. What is the best method for assessing lower limb force-velocity relationship? Int J Sports Med. 2015;36(2):143-149.

18. McKay JL, Welch TDJ, Vidakovic B, Ting LH. Statistically significant contrasts between EMG waveforms revealed using wavelet-based functional ANOVA. $J$ Neurophysiol. 2013;109:591-602.

19. Leontijevic B, Pazin N, Kukolj M, Ugarkovic D, Jaric S. Selective effects of weight and inertia on maximum lifting. Int J Sports Med. 2013;34:232-238.

20. Newton RU, Murphy AJ, Humphries BJ, Wilson GJ, Kraemer WJ, Häkkinen K. Influence of load and stretch shortening cycle on the kinematics, kinetics and muscle activation that occurs during explosive upper-body movements. Eur J Appl Physiol Occup Physiol. 1997;75:333-342.

21. Clark RA, Bryant AL, Humphries B. A comparison of force curve profiles between the bench press and ballistic bench throws. J Strength Cond Res. 2008;22:1755-1759.

22. Crewther B, Cronin J, Keogh J. Possible stimuli for strength and power adaptation: acute mechanical responses. Sports Med. 2005;35:967-989.

23. Baker D. A series of studies on the training of high-intensity muscle power in rugby league football players. J Strength Cond Res. 2001;15:198-209.

24. Cronin J, Sleivert G. Challenges in understanding the influence of maximal power training on improving athletic performance. Sports Med. 2005;35:213-234.

25. Bobbert MF. Effect of unloading and loading on power in simulated countermovement and squat jumps. Med Sci Sports Exerc. 2014;46:1176-1184.

26. Markovic G, Jaric S. Positive and negative loading and mechanical output in maximum vertical jumping. Med Sci Sports Exerc. 2007;39:1757-1764.

27. Behm DG, Sale DG. Velocity specificity of resistance training. Sports Med. 1993;15:374-388.

28. Samozino P, Rejc E, Di Prampero PE, Belli A, Morin J-B. Optimal force-velocity profile in ballistic movements--altius: citius or fortius? Med Sci Sports Exerc. 2012;44:313-322.

29. Jimenez-Reyes P, Samozino P, Cuadrado-Penafiel V, Conceicao F, Gonzalez-Badillo JJ, Morin JB. Effect of countermovement on power-force-velocity profile. Eur J Appl Physiol. 2014;114(11):2281-2288.

30. Samozino P, Edouard P, Sangnier S, Brughelli M, Gimenez P, Morin J-B. Forcevelocity profile: imbalance determination and effect on lower limb ballistic performance. Int J Sports Med. 2014;35:505-510. 
A

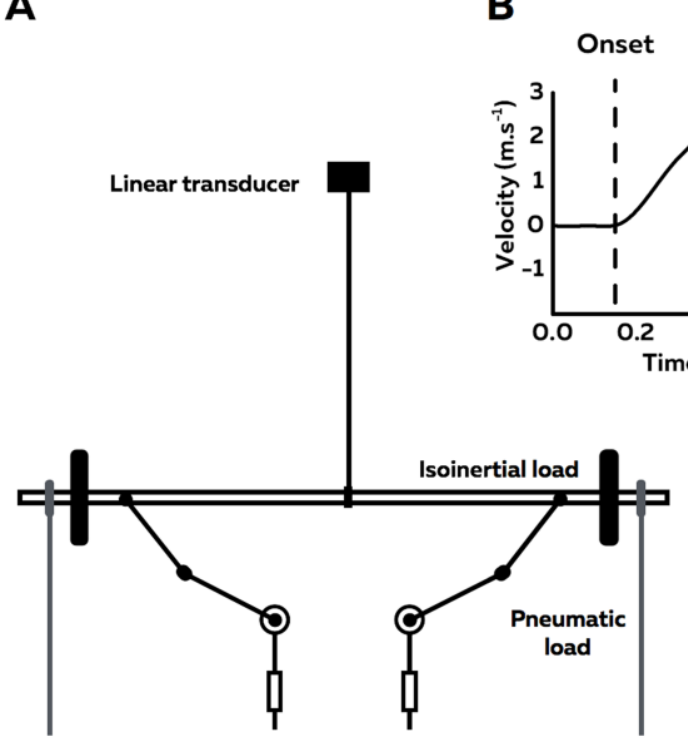

Signal Proceeding
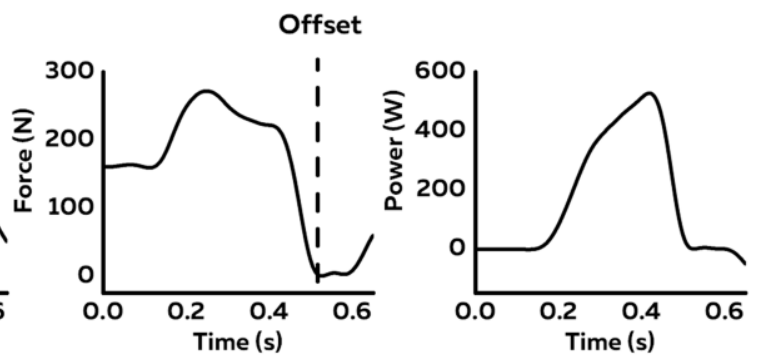

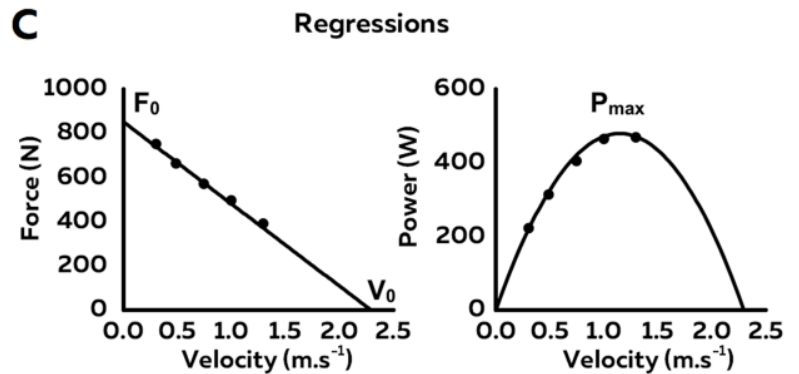

Figure 1. Overview of data acquisition and processing. A. Experimental Set Up B. Velocity, force and power patterns and detection of the onset and offset (dashed lines) of the concentric phase. C. Mean values were calculated after averaging force, velocity and power output between the onset and the offset of the concentric phase at all intensities (30\% to 90\% $1 \mathrm{RM})$. These mean values were used to build force-velocity and power-velocity relationships obtained with linear and polynomial regression, respectively. $\mathrm{x}$-intercept corresponds to maximal theoretical velocity $\left(\mathrm{V}_{0}\right)$ and y-intercept corresponds to maximal theoretical force $\left(\mathrm{F}_{0}\right)$ of the force-velocity relationship. Maximal power $\left(\mathrm{P}_{\max }\right)$ corresponds to the peak of power-velocity relationship. 

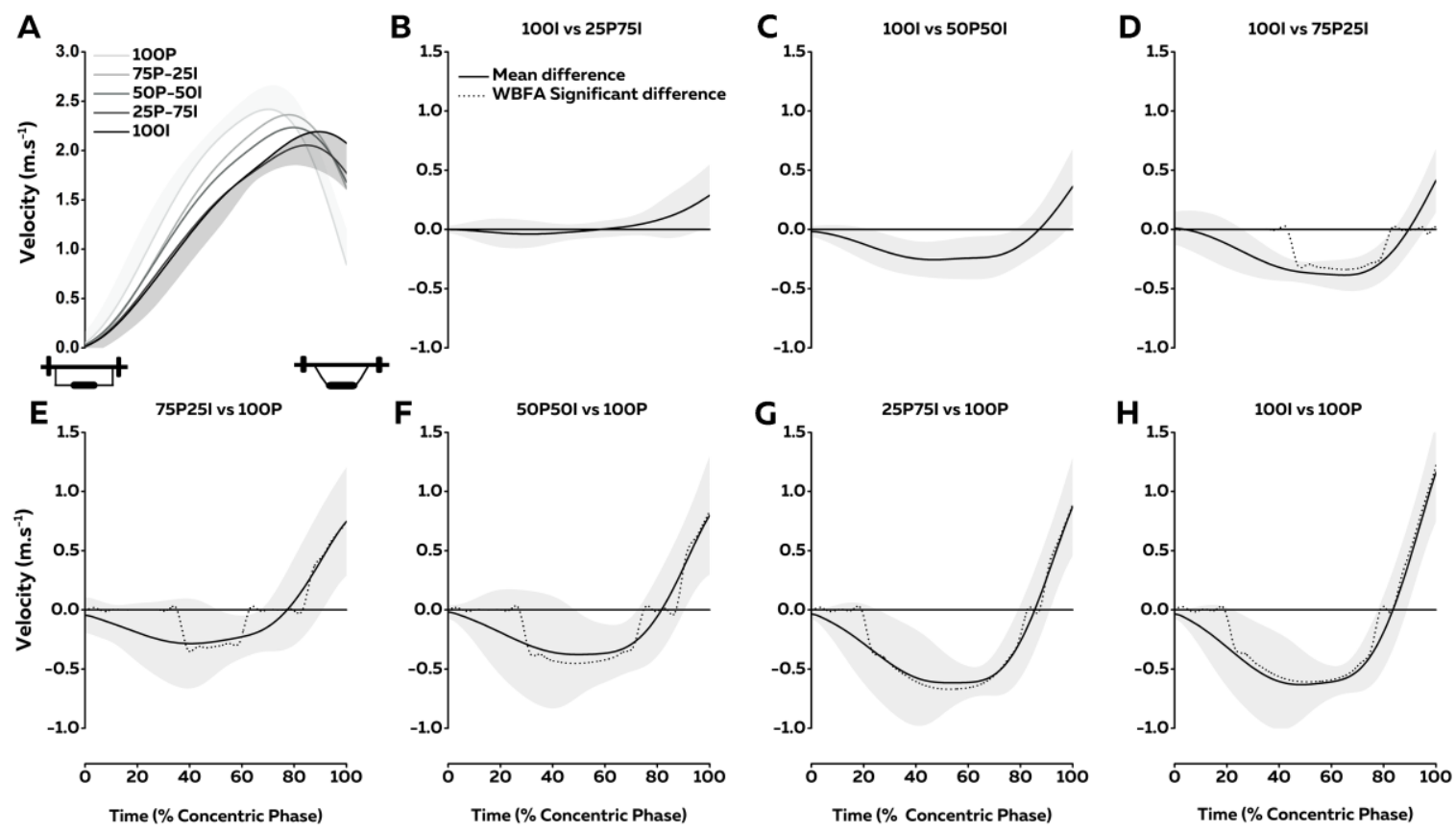

Figure 2. Movement velocity expressed as a percentage of the concentric phase at $30 \%$ 1RM. Values are presented as mean (line) \pm standard deviation (area). Values above the horizontal axis represent the superiority of isoinertial-oriented resistance and values below the horizontal axis represent the superiority of pneumatic-oriented resistance. Dashed lines display the inverse wavelet transform of the significant wavelets, thus indicating the statistically significant differences. 

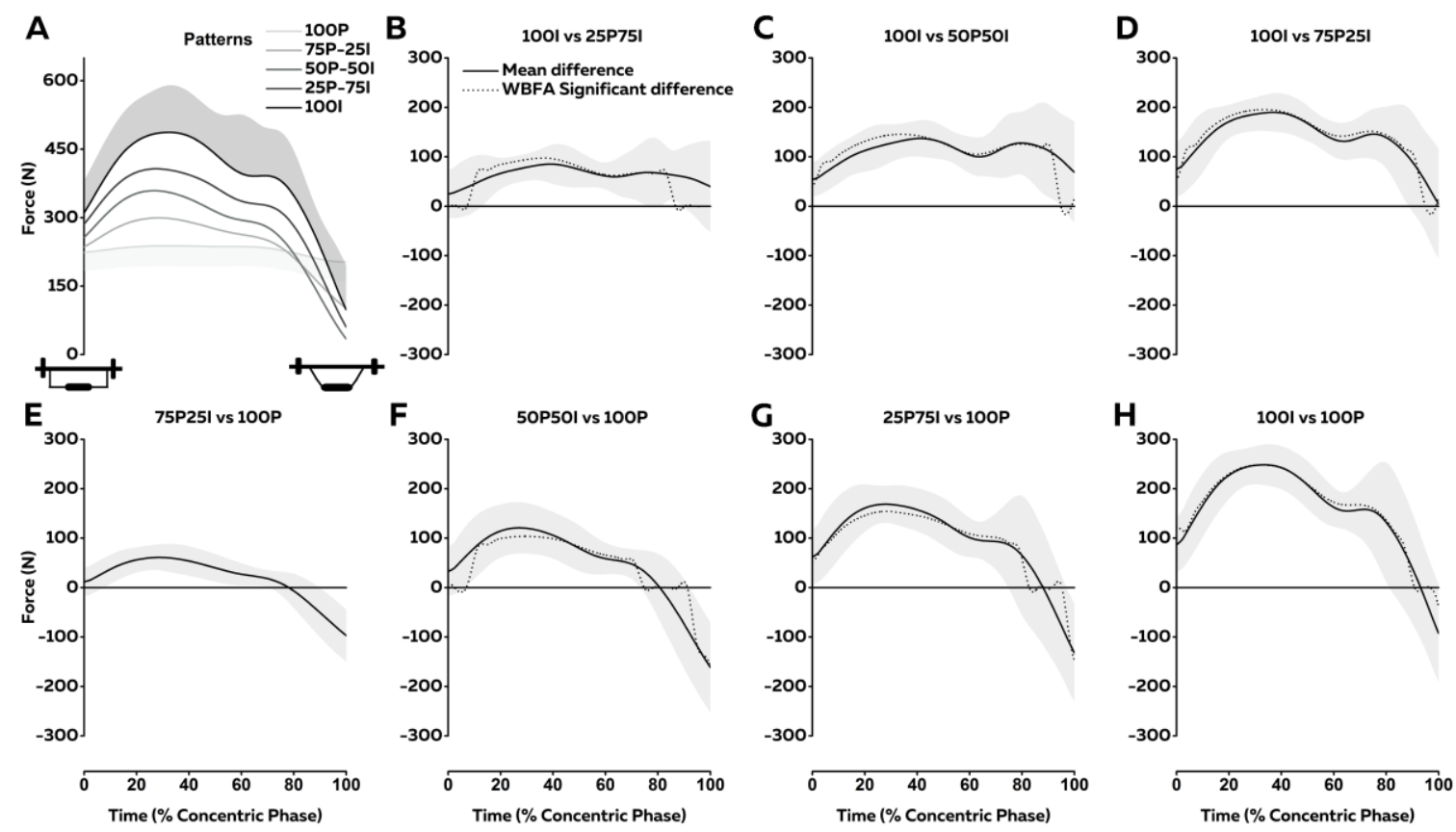

Figure 3. Force expressed as a percentage of the concentric phase at $30 \%$ 1RM. Values are presented as mean (line) \pm standard deviation (area). Values above the horizontal axis represent the superiority of isoinertial-oriented resistance and values below the horizontal axis represent the superiority of pneumatic-oriented resistance. Dashed lines display the inverse wavelet transform of the significant wavelets, thus indicating the statistically significant differences. 
A

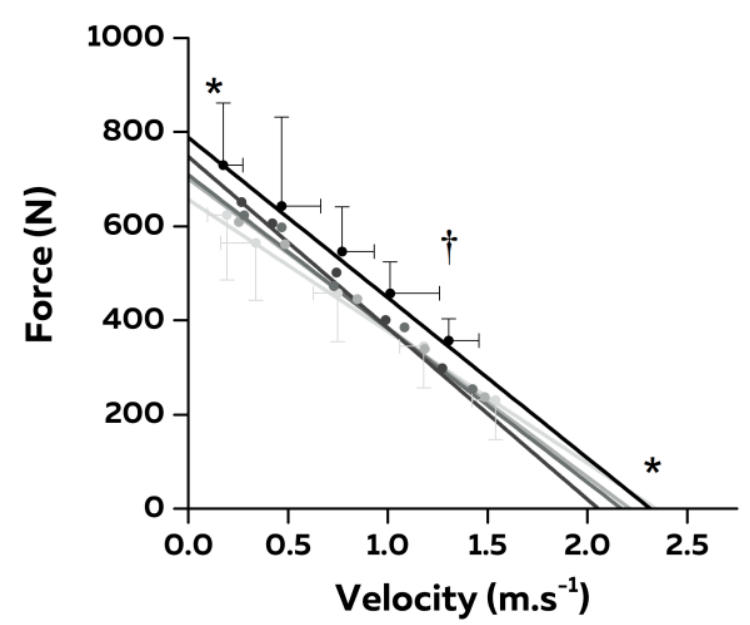

B

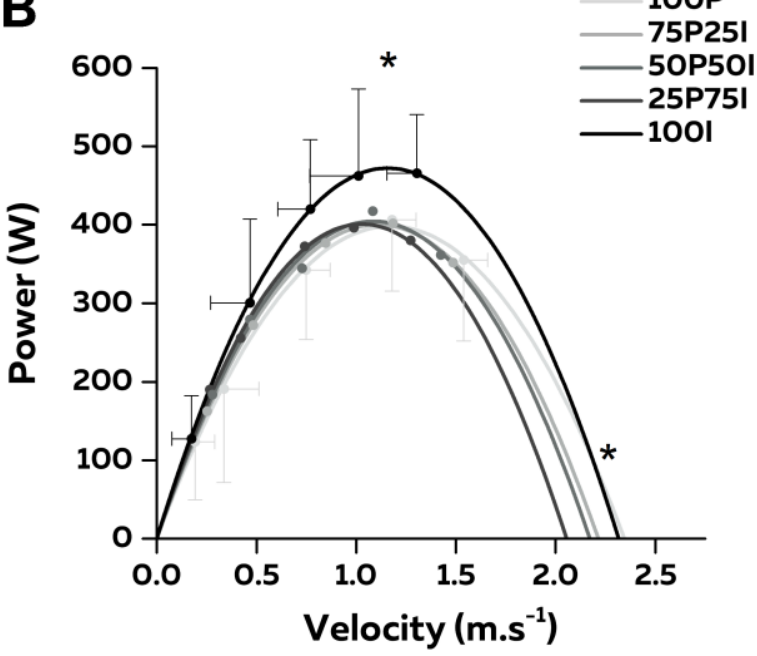

Figure 4. Effect of resistance ratio on force-velocity (A) and power-velocity (B) relationships. $\mathrm{x}$-intercept corresponds to maximal theoretical velocity $\left(\mathrm{V}_{0}\right)$ and $\mathrm{y}$-intercept corresponds to maximal theoretical force $\left(\mathrm{F}_{0}\right)$ of the force-velocity relationship. Maximal power $\left(\mathrm{P}_{\max }\right)$ corresponds to the peak of the power-velocity relationship. For the sake of clarity, only the main effect of resistance ratio was indicated. *, significant effect of resistance ratio on $\mathrm{F}_{0}, \mathrm{~V}_{0}$, or $\mathrm{P}_{\max }(P<0.05)$. $\dagger$, significant effect of resistance ratio on $\mathrm{S}_{\mathrm{FV}}(P$ $<0.05)$. 